\title{
Epidermal growth factor receptor first generation tyrosine-kinase inhibitors
}

\author{
Alex Martinez-Marti, Alejandro Navarro, Enriqueta Felip \\ Medical Oncology Department, Vall d'Hebron University Hospital and Vall d'Hebron Institute of Oncology (VHIO), Barcelona, Spain \\ Contributions: (I) Conception and design: All authors; (II) Administrative support: All authors; (III) Provision of study materials or patients: All \\ authors; (IV) Collection and assembly of data: All authors; (V) Data analysis and interpretation: All authors; (VI) Manuscript writing: All authors; (VII) \\ Final approval of manuscript: All authors. \\ Correspondence to: Dr. Enriqueta Felip. Medical Oncology Department, Vall d'Hebron University Hospital and Vall d'Hebron Institute of Oncology \\ (VHIO), P. Vall Hebron 119-129, 08035 Barcelona, Spain. Email: efelip@vhio.net.
}

\begin{abstract}
The epidermal growth factor receptor $(E G F R)$ oncogene was positioned as an attractive target for drug development in non-small cell lung cancer (NSCLC). Gefitinib and erlotinib were the first two reversible inhibitors of the EGFR kinase. The discovery of EGFR kinase domain-activating mutations that significantly correlated with a high likelihood of response to EGFR tyrosine-kinase inhibitors (TKIs) allowed to design studies to test these drugs as potential first-line therapies. In the same way, the feasibility of personalized medicine was established in patients with advanced NSCLC. Currently in the field of NSCLC with EGFR mutation have developed second and even third generation TKIs that would be gaining the positioning in the treatment of this subset population of NSCLC. In spite of this, without the knowledge that EGFR first generation TKIs have provided, we would not have gotten so far. We will review step by step how it was forged the exciting history of the subpopulation of lung cancer with EGFR mutated, through the various clinical trials performed with first generation TKIs that changed the focus, the future of NSCLC as well as survival of these patients.
\end{abstract}

Keywords: Non-small cell lung cancer (NSCLC); epidermal growth factor receptor mutations (EGFR mutations); erlotinib; gefitinib

Submitted Apr 03, 2019. Accepted for publication Apr 25, 2019.

doi: $10.21037 /$ tlcr.2019.04.20

View this article at: http://dx.doi.org/10.21037/tlcr.2019.04.20

Oncogene addiction is a concept used to emphasize the dependence of certain tumors on one or a few genes for the maintenance of the malignant phenotype (1-3).

This phenomenon can trigger amazing clinical responses, more specifically in certain subtypes of non-small cell lung cancers (NSCLC) treated with targeted kinase inhibitors whose target is the epidermal growth factor receptor (EGFR) (4). The identification of EGFR as an oncogene led to the development EGFR inhibitors. The superfamily of ERBB or EGFRs comprises four members: EGFR/ ERBB1, HER-2/ERBB2, ERBB3 and ERBB4. All of them have an extracellular ligand-binding domain, a hydrophobic transmembrane region and a cytoplasmic tyrosine-kinase (TK) domain. Ligand binding to ERBB receptors induces the formation of receptor homodimers and heterodimers and successively the activation of the intrinsic kinase domain. As a result, it generates the phosphorylation on specific residues within the cytoplasmic tail. These residues after his recruitment leads to the activation of intracellular signalling pathways (5).

The EGFR signaling network, a key engine assisting of normal cell growth and differentiation of dependent tissues, also plays a significant role in promoting proliferation of malignant cells after aberrant EGFR activations. EGFR expression is common in NSCLC patients, in up to $90 \%$ of squamous cell carcinoma histology as well as in 30-65\% of adenocarcinoma subtype (6,7). According to this data, EGFR was positioned as an attractive target in NSCLC. 
Table 1 Single agent phase I studies with gefitinib and erlotinib

\begin{tabular}{|c|c|c|c|c|c|c|}
\hline Agent & Tumor type & No. of pts & Dose & Regimen & MTD (mg/d) & DLT toxicities \\
\hline Erlotinib (9) & All & 28 & $100-1,600 \mathrm{mg} /$ week & Days $1,8,15$ q4wk & Not reached & Diarrhea \\
\hline Gefitinib (11) & All & 88 & $150-1,000 \mathrm{mg} / \mathrm{d}$ & Continuous & Not reached & $\begin{array}{c}\text { Diarrhea, somnolence, } \\
\text { skin rash }\end{array}$ \\
\hline Gefitinib (13) & All & 64 & $50-925 \mathrm{mg} / \mathrm{d}$ & 14 consecutive days every $28 \mathrm{~d}$ & 700 & Diarrhea \\
\hline Gefitinib (14) & All & 28 & $150-800 \mathrm{mg} / \mathrm{d}$ & Continuous & Not reached & Diarrhea \\
\hline Gefitinib (15) & All & 31 & $50-925 \mathrm{mg} / \mathrm{d}$ & 14 consecutive days every $28 \mathrm{~d}$ & 700 & Diarrhea, skin rash \\
\hline
\end{tabular}

DLT, dose-limiting toxicity.

The low-molecular-weight tyrosine-kinase inhibitors (TKIs) compete with adenosine triphosphate (ATP) to bind intracellularly in the catalytic cleft of the TK domain, causing suppression of receptor phosphorylation and downstream signaling. Due to EGFR TKIs rational, were thought to be useful for the majority of cases with NSCLC, but their clinical development led to the identification of a novel subpopulation of NSCLC patients (8).

The first two EGFR TKIs, erlotinib and gefitinib embarked on the first phase I clinical trials in the early 2000s (9-15). Both are orally administration anilinoquinazolines that selectively and reversibly prevent ATP binding and therefore act inhibiting EGFR autophosphorylation $(16,17)$. After the data obtained from the different phase I trials whose confirmed the feasibility of oral administration on a daily, continuous, uninterrupted schedule, objectifying well tolerability, good safety profile and encouraging preliminary activity in NSCLC patients; tumor-specific phase II trials were explored (Table 1) .

Therefore, the maximum-tolerated dose (MTD) defined by phase I trial $(150 \mathrm{mg} / \mathrm{d})$ was the selected dose to continue the development of erlotinib; while 250 and $500 \mathrm{mg}$ were the gefitinib chosen doses for assessment of antitumor activity in phase II trials. The three most important specific phase II studies in advanced NSCLC previously treated population released response rates (RR) to single agent TKI (erlotinib/gefitinib) around $10-18 \%$ with a favorable safety profile, being the skin rash and diarrhea the most common side effects.

The first one, published by Pérez-Soler et al., was a single-arm, open-label, multicenter phase II study with continuous daily dose of $150 \mathrm{mg}$ of erlotinib in fifty- seven advanced NSCLC patients previously treated with platinum-based chemotherapy (CT) and HER1/EGFR overexpressed (18). The overall RR was $12.3 \%$ (95\% CI, $5.1 \%$ to $23.7 \%$ ) and with a remarkable median overall survival (mOS) of 8.4 months (95\% CI, 4.8 to 13.9 months).

The second one, the Iressa Dose Evaluation in Advanced Lung Cancer (IDEAL 1) trial was a randomized, doubleblind, parallel-group study conducted in Europe, Australia, South Africa, and Japan (19). This multicenter phase II trial assessed the safety and efficacy of daily doses of 250 and $500 \mathrm{mg}$ of gefitinib in advanced NSCLC patients who had previously received one or two CT regimens. Objective tumor RR were $18.4 \%$ (95\% CI, 11.5 to 27.3 ) for the $250 \mathrm{mg} / \mathrm{d}$ group and $19.0 \%$ (95\% CI, 12.1 to 27.9 ) for the $500 \mathrm{mg} / \mathrm{d}$ group; and median OS times were 7.6 months (95\% CI, 5.3 to 10.1 ) and 8.0 months (95\% CI, 6.7 to 9.9), respectively.

Last but not least, the IDEAL 2 trial was a randomized, double-blind study conducted in USA (20). This phase II trial assessed the efficacy on everyday prescription of 250 and $500 \mathrm{mg}$ of gefitinib in patients with advanced NSCLC who had received at least two previous CT regimens that included platinum and docetaxel. Tumor RR were $12 \%$ (95\% CI, 6 to 20) for the $250 \mathrm{mg} / \mathrm{d}$ group and $9.0 \%$ (95\% CI, 4 to 16) for the $500 \mathrm{mg} / \mathrm{d}$ group; and median OS times were 7.0 and 6.0 months, respectively (Table 2).

Based on the IDEAL trials data and the "orphan indication" of third-line therapy for NSCLC, gefitinib $(250 \mathrm{mg} / \mathrm{d})$ obtained US Food and Drug Administration (FDA) approval in May, 2003, for use as monotherapy in advanced NSCLC patients after treatment with CT enclosing a platinum agent or docetaxel. 
Table 2 Single agent phase II studies with gefitinib and erlotinib in NSCLC pts

\begin{tabular}{|c|c|c|c|c|c|c|}
\hline Trial & Agent & No. of pts & Median OS (months) & $\mathrm{RR}(\%)$ & Toxicities (\%) & Comments \\
\hline \multirow[t]{3}{*}{ IDEAL 1} & Gefitinib & 210 & & & \multirow{3}{*}{$\begin{array}{c}\text { Rash } 59.2 \text { vs. 82.9; } \\
\text { diarrhea } 39.8 \text { vs. } 57.6\end{array}$} & \multirow{3}{*}{$\begin{array}{l}\text { Random, double-blind, prior } \\
\text { platinum }\end{array}$} \\
\hline & $250 \mathrm{mg} / \mathrm{d}$ & & 7.6 & 18.4 & & \\
\hline & $500 \mathrm{mg} / \mathrm{d}$ & & 8 & 19 & & \\
\hline \multirow{2}{*}{ IDEAL 2} & $250 \mathrm{mg} / \mathrm{d}$ & & 7 & 12 & \multirow{2}{*}{$\begin{array}{c}\text { Rash } 62 \text { vs. } 75 \text {; diarrhea } \\
57 \text { vs. } 75\end{array}$} & \multirow{2}{*}{$\begin{array}{l}\text { Random, double-blind, prior } \\
\text { platinum }\end{array}$} \\
\hline & $500 \mathrm{mg} / \mathrm{d}$ & & 6 & 9 & & \\
\hline
\end{tabular}

NSCLC, non-small cell lung cancer.

During the period that the expanded use program was open, it was objectified by various groups that certain clinical/epidemiologic patient features (adenocarcinoma histology, East Asian ethnicity, a history of never smoking, female gender and the appearance of rash with the treatment) predisposed to better respond to the TKI (21-24).

Into the design of randomized phase III trials with EGFR TKIs in NSCLC, a first strand of studies were focused on the combination of platinum-based CT given concurrently with TKI compared with CT and placebo in first-line.

The first phase III study reported with gefitinib was the Iressa NSCLC Trial Assessing Combination Therapy (INTACT 1), which the CT designed was cisplatin/ gemcitabine (25). A total amount of 1,093 patients were enrolled and unfortunately there were no differences in efficacy end points between the three treatment groups. For the gefitinib $500 \mathrm{mg} / \mathrm{d}$, gefitinib $250 \mathrm{mg} / \mathrm{d}$, and placebo groups, respectively, median OS (primary endpoint) were 9.9, 9.9, and 10.9 months (global ordered log-rank $\mathrm{P}=0.4560$ ), and RR were $50.3 \%, 51.2 \%$, and $47.2 \%$ ( $\mathrm{P}=$ not significant). Gefitinib in combination with cisplatin/gemcitabine in advanced NSCLC patients CT-naive did not show improved efficacy over standard cisplatin/gemcitabine alone.

The INTACT 2 was a randomized, placebo-controlled phase III trial of carboplatin/paclitaxel with or without gefitinib in advanced NSCLC CT-naive patients (26). A total of 1,037 patients were recruited and again, no difference was found in OS (median 8.7, 9.8, and 9.9 months for gefitinib $500 \mathrm{mg} / \mathrm{d}$, gefitinib $250 \mathrm{mg} / \mathrm{d}$, and placebo groups, respectively; $\mathrm{P}=0.64)$. Overall $\mathrm{RR}$ were $30.0 \%, 30.4 \%$, and $28.7 \%$, respectively, indicating no statistically significant efficacy difference between treatment arms.
Consistent with data of the INTACT trials, the results for similarly designed studies with erlotinib in combination with CT were also negative (27).

The phase III trial, designed TRIBUTE (Tarceva Responses in Conjunction with Paclitaxel and Carboplatin), was a randomized, placebo-controlled study of carboplatin/ paclitaxel with or without erlotinib in CT-naive patients with advanced NSCLC (28). A total of 1,079 patients were randomly assigned. Erlotinib with carboplatin/paclitaxel did not confer a survival benefit over carboplatin/paclitaxel alone. Median OS was 10.6 months in the erlotinib arm and 10.5 months in the placebo arm (hazard ratio, $0.995 ; 95 \%$ CI, 0.86 to $1.16 ; \mathrm{P}=0.95)$. The objective $\mathrm{RR}$ were $21.5 \%$ and $19.3 \%$, respectively $(\mathrm{P}=0.36)$.

The TArceva Lung cancEr iNvesTigation outside the USA (TALENT) phase III study was a randomized, placebo-controlled trial of cisplatin/gemcitabine with or without erlotinib in patients with previously untreated advanced NSCLC (29). A total of 1,172 patients were enrolled. Erlotinib in combination with cisplatin/ gemcitabine did not show any survival benefit compared with CT alone; median OS was 43 weeks for erlotinib arm and 44.1 weeks in the placebo arm [hazard ratio (HR), 1.06; 95\% CI, 0.90 to $1.23 ; \mathrm{P}=0.49]$. The objective $\mathrm{RR}$ were $31.5 \%$ and $29.9 \%$, respectively (Table 3).

The second type of design of the randomized phase III studies with EGFR TKI in NSCLC was aimed at testing TKI in monotherapy compared with placebo in the secondor third-line setting.

The BR.21 phase III trial, was a randomized, placebocontrolled study of best supportive care (BSC) with erlotinib or placebo in NSCLC after the failure of firstline or second-line CT (30). A total amount of 731 patients 
Table 3 Phase III trials of combination with platinum-based CT and EGFR TKI in 1st-line

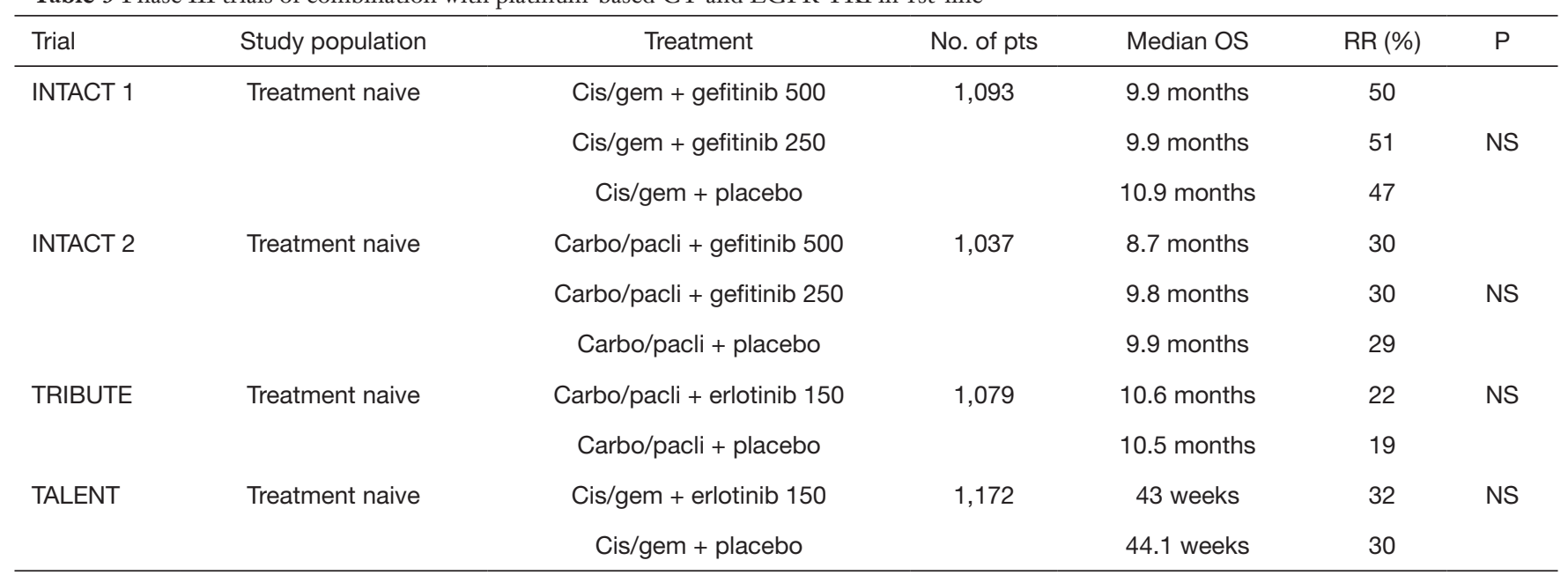

NS, not significant; EGFR, epidermal growth factor receptor; TKI, tyrosine-kinase inhibitor; RR, response rates.

Table 4 Phase III trials with EGFR TKI compared with placebo in 2nd- or 3rd-line

\begin{tabular}{|c|c|c|c|c|c|c|c|}
\hline Trial & Study population & Treatment & No. of pts & Median OS (months) & $\mathrm{HR}(95 \% \mathrm{Cl})$ & Log-rank P & $\mathrm{RR}(\%)$ \\
\hline BR.21 & & Placebo & & 4.7 & & & 1.0 \\
\hline \multirow[t]{2}{*}{ ISEL } & Prior platinum & Gefitinib 250 & 1,692 & 5.6 & $0.89(0.77-1.02)$ & 0.087 & 8.0 \\
\hline & & Placebo & & 5.1 & & & 1.3 \\
\hline
\end{tabular}

EGFR, epidermal growth factor receptor; TKI, tyrosine-kinase inhibitor; OS, overall survival; HR, hazard ratio; RR, response rates.

were randomly (2:1 ratio). Erlotinib did provide clinically meaningful prolongation of survival, as compared with placebo, in previously treated patients with advanced NSCLC. Overall survival was 6.7 months in the erlotinib group and 4.7 months in the placebo group (HR, 0.70; 95\% CI, 0.58-0.85, $\mathrm{P}<0.001)$. The RR was $8.9 \%$ and less than $1 \%$, respectively $(\mathrm{P}<0.001)$.

The Iressa Survival Evaluation in advanced Lung Cancer (ISEL) trial was planned to assess BSC with gefitinib $250 \mathrm{mg} / \mathrm{d}$ or placebo in NSCLC patients who had been treated previously (31). In this randomized, doubleblind, placebo-controlled, phase III study a total of 1,692 patients were randomly (2:1 ratio). Gefitinib was not associated with a significant raise in OS in either the whole or adenocarcinoma coprimary population. In the total population, median OS in the gefitinib group was 5.6 and 5.1 months in the placebo group (HR 0.89; 95\% CI, 0.77$1.02, \mathrm{P}=0.087)$. Among adenocarcinoma population, median OS was 6.3 months and 5.4 months, respectively (HR 0.84; $95 \%$ CI, 0.68-1.03, $\mathrm{P}=0.089)$. The objective RR in the total population was significantly higher in the reversible TKI group than in the placebo group $(8.0 \%$ vs. $1.3 \%$; odds ratio 7.28, 95\% CI, 3.1-16.9, $\mathrm{P}<0.0001$ ) (Table 4).

The BR.21 and ISEL trials used a similar design although with divergent results between the two drugs. Surprisingly, HR for mOS for erlotinib and gefitinib compared with placebo differ. The BR.21 study demonstrated a survival benefit with erlotinib, and with great astonishment for the oncological community, the ISEL study failed to show such benefit with gefitinib. It is uncertain why BR.21 study revealed a survival benefit with erlotinib while ISEL trial failed to prove such benefit with gefitinib. It should be indicated that erlotinib was managed at its MTD, while gefitinib was administered at only one third of its MTD. On the other hand, different populations with respect to clinical or molecular characteristics enrolled in the two trials could be another justification.

Concerning results from BR.21 trial, erlotinib received the approval by FDA for patients with advanced, previously treated NSCLC as a second- or third-line treatment in 
November, 2004. Contrary, based on the negative results of ISEL trial published in December, 2004, the FDA limited the use of gefitinib to patients participating in a clinical trial or those who had previously profited from it.

In the same period, three research groups determined to give a molecular reason for that small subpopulation of NSCLC patients with clinical/epidemiologic characteristics predisposed to better respond to the TKI, elucidated that phenomenon. In 2004 they published, practically simultaneously, the discovery of specific EGFR kinase domain-activating mutations that significantly correlated with a high likelihood of response to EGFR TKIs (32-34).

Lynch et al. (32) tested and confirmed the association between the dramatic drug responses to gefitinib with somatic mutations in the TK domain of EGFR in NSCLC patients. Likewise, and consistent with prior communications, the most cases with a response to gefitinib were women, never smokers and bronchoalveolar tumors. Paez et al. (33) carried out the screening of somatic EGFR mutations in 119 samples from untreated patients with NSCLC. They found mutations in five out of five gefitinibresponsive cases. Pao et al. (34) confirmed these findings in erlotinib-responsive cases. From there, retrospective series corroborated EGFR mutations as a molecular predictors of response to EGFR TKIs as well as its incidence and distribution according to clinical variables (23,35-46). The more common EGFR mutations are exon 19 in-frame deletions and the single point mutation $L 858 R$ in exon 21 . According to the different kind of EGFR mutations could respond differently to EGFR TKIs (47). The exon 19 deletions would be linked with a better response than the L858R substitution (48). The Identification of an EGFR mutation that could be used to select a subgroup of NSCLC patients with highly responsive to EGFR TKIs was the trigger and provided the urge for the rational design of clinical trials in selected, EGFR-mutated patient cohorts.

With this rational, several phase II clinical trials were published using EGFR mutation screening to select a population of advanced NSCLC CT-naive patients harboring EGFR mutations for first-line treatment with EGFR-TKIs (49-52).

Inoue et al. (49) screened EGFR gene status of seventyfive samples obtained from Asian advanced NSCLC patients. Twenty-five of them (33\%) harbored EGFR mutations, and sixteen (64\%) of these patients with EGFR mutations were enrolled receiving gefitinib. The overall $\mathrm{RR}$ in these patients was $75 \%$ (95\% CI, 54\% to $96 \%$ ). The median progression-free survival (PFS) was 9.7 months
(95\% CI, 7.4 to 9.9 months) in the 16 patients included in this trial.

Asahina and colleagues (50) conducted a similar phase II study to examine the efficacy of gefitinib as first-line therapy for advanced NSCLC Japanese patients with EGFR mutations. In twenty (24\%) of the eighty-two screened patients identified EGFR mutations. Of these, sixteen (80\%) patients were treated with gefitinib and achieved a RR of $75 \%$ (95\% CI, 48-93\%). The median PFS was 8.9 months (95\% CI, 6.7-11.1 months).

Tamura et al. (51) published the prospective phase II study (WJTOG0403) with the purpose to assess the efficacy of gefitinib and the feasibility of screening for EGFR mutations among select patients with advanced NSCLC and CT-naive or those who had previously received up to two prior CT regimens. One hundred eighteen patients were screened for $E G F R$ mutations, which were detected in thirty-two (27\%). Twenty-eight (88\%) of whom received gefitinib. The overall RR was $75 \%$ (95\% CI, 57.6-91.0\%). The median PFS was 11.5 months.

Sequist et al. (52) performed a similar phase II prospective trial (iTARGET) in North American patients. Ninety-eight CT-naive patients with advanced NSCLC were screened and mutations were detected in thirty-four (35\%). Thirty-one (91\%) patients received gefitinib. The RR was $55 \%$ (95\% CI, 33\% to $70 \%$ ) and mPFS was 9.2 months (95\% CI, 6.2 to 11.8 months) (Table 5).

In order to demonstrate the feasibility of performing the screening for EGFR mutations in clinical practice, the Spanish Lung Cancer Group reported a prospective study of screening for EGFR mutations in advanced NSCLC patients using a central laboratory and database (53). They were prospectively screened a total amount of 2,105 samples of tumor tissue from patients with NSCLC for EGFR mutations. Mutations in the EGFR gene were detected in 350 patients (16.6\%), and 296 of them were at that moment considered for customized erlotinib treatment at a dose of $150 \mathrm{mg} / \mathrm{d}$. Of these patients, $79 \mathrm{did}$ not receive the EGFR TKI for a variety of motives. Of the 217 patients who received erlotinib, 197 could be evaluated for a response. The RR was $70.6 \%$. The median PFS for the 217 patients treated with erlotinib (as first-, second-, or third-line therapy) was 14.0 months (95\% CI, 11.3 to 16.7 ). The median OS was 27.0 months (95\% CI, 22.7 to 31.3). They demonstrated that large-scale screening of patients for EGFR mutations was feasible and that it could be a useful tool in daily practice with a great repercussion on the selection of patients who would benefit from treatment with 
Table 5 Phase II trials with EGFR TKI in first-line NSCLC pts harboring EGFR mutations

\begin{tabular}{|c|c|c|c|c|c|c|c|}
\hline Trial & Study population & Treatment & No. of pts screened & EGFR mut & No. pts treated & $\mathrm{RR}(\%)$ & mPFS (months) \\
\hline Asahina & CT-naive & Gefitinib & 82 & 20 & 16 & 75 & 8.9 \\
\hline WJTOG0403 & $\mathrm{CT}$ naive or up to 2 prior $\mathrm{CT}$ & Gefitinib & 118 & 32 & 28 & 75 & 11.5 \\
\hline iTARGET & CT naive & Gefitinib & 98 & 34 & 31 & 55 & 9.2 \\
\hline
\end{tabular}

EGFR, epidermal growth factor receptor; TKIs, tyrosine-kinase inhibitors; NSCLC, non-small cell lung cancer; RR, response rates.

\section{EGFR TKIs.}

These studies confirmed that treatment with EGFR first generation TKIs alone for CT-naive NSCLC patients with EGFR mutations was safe and produced durable responses in a high proportion of patients. However, this approach should be compared with the current standard of care, platinum-doublet CT.

To validate this strategy, in a subpopulation of advanced NSCLC patients that harbored EGFR mutations, several randomized phase III trials in first-line compared standard platinum-based CT with reversible EGFR TKIs.

IPASS (the Iressa Pan-Asia Study) was the earliest randomly trial that proved the benefit of first-line EGFR TKI (gefitinib) above carboplatin plus paclitaxel in East Asian patients with advanced pulmonary adenocarcinoma and who were nonsmokers or former light smokers (54). A total of 1,217 patients were randomly assigned to a study group. EGFR mutation data for 437 samples of tumor tissue from patients could be evaluated. Of these samples, 261 were positive for an EGFR mutation. The main end point of improvement in PFS was accomplished (HR $0.74 ; 95 \%$ CI, 0.65 to 0.85 ) in this clinically selected East Asian population. In the subpopulation positive for EGFR mutation, the PFS was greatly longer among the gefitinib group than those receiving CT (HR 0.48; $95 \% \mathrm{CI}, 0.36$ to $0.64 ; \mathrm{P}<0.001)$. The $\mathrm{RR}$ in the overall population was statistically higher with the TKI than with chemotherapy $(43.0 \%$ vs. $32.2 \%$; odds ratio 1.59 ; $95 \%$ CI, 1.25 to $2.01 ; \mathrm{P}<0.001)$. In the $E G F R$ mutation-positive subgroup, the RR was $71.2 \%$ with the TKI vs. $47.3 \%$ with CT $(\mathrm{P}<0.001)$. The OS in the ahead of schedule analysis [ 450 patients $(37.0 \%)$ died] was similar among the two groups in the overall population.

First-SIGNAL (First-Line Single-Agent Iressa Versus Gemcitabine and Cisplatin Trial in Never-Smokers With Adenocarcinoma of the Lung) was a Korean trial with a similar design to that of IPASS, and the main end point was OS (55). A total of 313 Korean never-smokers patients with advanced adenocarcinoma were randomly assigned to receive either gefitinib or gemcitabine and cisplatin (GP) CT (309 patients were analyzed). Gefitinib failed to demonstrate superior OS compared with GP (HR 0.932; $95 \%$ CI, 0.716 to $1.213 ; \mathrm{P}=0.604$; median OS, 22.3 vs. 22.9 months, respectively). The median PFS was 5.8 months in the TKI arm and 6.4 months in the CT arm (HR 1.198; $95 \%$ CI, 0.944 to $1.520 ; \mathrm{P}=0.138)$. EGFR mutation data for 96 samples of tumor tissue from patients could be evaluated. Of these samples, 42 were positive for a $E G F R$ mutation. In the EGFR mutation-positive subgroup, the gefitinib arm proved a higher overall RR $(84.6 \%$ vs. $37.5 \%$, respectively; $\mathrm{P}=0.002)$. However, PFS did not have statistical significance (HR 0.544; $95 \%$ CI, 0.269 to $1.100 ; \mathrm{P}=0.086$ ).

The other five randomized phase III trials only enrolled NSCLC patients with known activating EGFR mutations.

The WJTOG3405 was a randomized, phase 3 trial of first-line treatment with gefitinib compared to cisplatin plus docetaxel for Japanese population with metastatic NSCLC harbouring an activating mutation of the EGFR gene (56). A total of 177 CT-naive patients were randomly assigned although five were excluded (thus, 172 patients were incorporated in the survival analyses). Gefitinib treatment resulted in significantly longer PFS than cisplatin plus docetaxel, with a median PFS of 9.2 vs. 6.3 months, respectively (HR 0.489; 95\% CI, 0.336-0.710; $\mathrm{P}<0.0001$ ). The objective RR in the overall population was $62.1 \%$ in the reversible EGFR TKI group and $32.2 \%$ in the CT group $(\mathrm{P}<0.0001)$. After five-year follow-up overall survival analysis, there was no difference in OS whether the initial treatment was gefitinib or cisplatin plus docetaxel, probably due to cross over rate (57).

The NEJ002, phase III trial, randomly assigned 230 Japanese patients (two patients were excluded) with advanced NSCLC and sensitive EGFR mutations to receive gefitinib or carboplatin plus paclitaxel in first-line 
treatment (58). The preplanned interim analysis was carried out four months after the 200th participant was enrolled, showing that PFS was significantly longer in the reversible EGFR TKI group than in the CT group (HR for death or disease progression with gefitinib, 0.36 ; $95 \% \mathrm{CI}, 0.25$ to $0.51 ; \mathrm{P}<0.001$ ), resulting in early termination of the study. A significant variation was noted in the final analysis in favor of the gefitinib group with median PFS of $10.8 \mathrm{vs}$. 5.4 months, respectively (HR $0.30 ; 95 \%$ CI, 0.22 to 0.41 ; $\mathrm{P}<0.001)$. The objective $\mathrm{RR}$ was significantly higher in the gefitinib arm than the CT arm $(73.7 \%$ vs. $30.7 \%, \mathrm{P}<0.001)$. No significant difference in OS was observed among the two treatment groups, likely due to a elevated crossover use of gefitinib in the CT group. For all 228 NEJ002 trial patients, survival data were updated in December, 2010 (59). The median survival time was 27.7 months for the gefitinib group, and was 26.6 months for the carboplatin plus paclitaxel group (HR 0.887; 95\% CI, 0.634 to 1.241; $\mathrm{P}=0.483$ ).

OPTIMAL (CTONG-0802) was the earliest randomized, head-to-head phase III study that examined the efficacy and safety of first-line erlotinib versus platinum doublet CT in Chinese patients with advanced NSCLC whose tumors harboured activating mutations in EGFR (60). A total of 549 patients were screened for EGFR mutations and 165 were randomly assigned to treatment groups. Regarding these patients, measurable disease was available in 154 of them and they received at least one dose of study drug (82 erlotinib, 72 carboplatin plus gemcitabine). First-line erlotinib treatment was associated with significantly longer PFS compared with CT. Median PFS was 13.1 months in erlotinib arm vs. 4.6 months for patients receiving carboplatin plus gemcitabine (HR 0.16, 95\% CI, 0.10 to $0.26 ; \mathrm{P}<0.0001)$. The overall $\mathrm{RR}$ was $83 \%$ for the EGFR TKI and $36 \%$ for CT $(\mathrm{P}<0.0001)$. Final OS analysis was planned when $70 \%$ of deaths had occurred in the intent-to-treat population. Events for OS analysis were met in December, 2012 (61). Median OS was resembling between both groups (22.8 and 27.2 months, respectively) with no significant differences (HR 1.19; $95 \%$ CI, 0.83 to $1.71 ; \mathrm{P}=0.2663)$.

The EURTAC, a randomized phase III trial, was aimed to assess the efficacy and safety of first-line erlotinib compared with standard CT for European patients with advanced EGFR-mutation positive NSCLC (62). A total of 1,227 patients from 42 centres in Spain, Italy, and France were screened for EGFR mutations. Finally 173 European patients with $E G F R$ mutations were randomized to receive erlotinib (86 patients) or standard CT (87 patients). The preplanned interim analysis indicated that the EURTAC trial met its main endpoint of the PFS (HR 0.42, 95\% CI 0.27 to $0.64 ; \mathrm{P}<0.0001)$. In the final analysis, median PFS was 9.7 months in the erlotinib group and 5.2 months in the standard CT group (HR 0.37, 95\% CI, 0.25 to 0.54 ; $\mathrm{P}<0.0001)$. The confirmed $\mathrm{RR}$ was $64 \%$ in the reversible EGFR TKI arm and $18 \%$ in the standard arm. No major differences in OS between the two groups were appreciated.

Finally, the randomized, phase III ENSURE trial assessed first-line erlotinib versus cisplatin plus gemcitabine in patients from China, Malaysia and the Philippines with EGFR mutation-positive NSCLC (63). The rationale was to provide further proof of efficacy with first-line erlotinib in Asian population with EGFR mutation-positive NSCLC. A total of 217 Asian patients were randomized. When $73 \%$ of PFS events had occurred, the preplanned interim analysis was conducted. Investigator-assessed median PFS was 11.0 months for erlotinib arm and 5.5 months for CT arm (HR 0.34, 95\% CI, 0.22 to 0.51 ; log-rank $\mathrm{P}<0.0001$ ). The ORR was $62.7 \%$ for erlotinib and $33.6 \%$ for cisplatin plus gemcitabine. Median OS was not significantly different between the two groups, 26.3 for reversible EGFR TKI vs. 25.5 months for CT (HR, 0.91, 95\% CI, 0.63 to 1.31; $\log$-rank $\mathrm{P}=0.607)$. One explanation would be that $85.6 \%$ of Asian patients randomized to the $\mathrm{CT}$ arm received further treatment with EGFR TKIs compared with $59.1 \%$ of the erlotinib arm receiving CT (Table 6).

Six randomized phase III trials had demonstrated enhancement in PFS and in tumor RR with EGFR firstgeneration TKIs over platinum-based chemotherapy in this biomarker-selected population. In the same way, the feasibility of personalized medicine was established in patients with advanced NSCLC. Nevertheless, not any study was capable to prove an OS enhancement with the reversible EGFR TKIs, probably due to cross over rate. Overall, the first-generation TKIs were tolerable, with characteristic adverse events including class-related gastrointestinal and skin toxicities. A selection of patients, was recommended on the basis of EGFR-mutation status thereafter. A new era of molecular diagnosis and personalized medicine was dawning and involving a fast and fascinating outcrop of new therapeutic targets as well as continuous improvement of new generation drugs. Knowing where we came from, and with the progress achieved, new strategies to improve the results of EGFR TKIS first generation began to see the light.

One of the strategies to improve survival was the 
Table 6 Prospective randomized phase III studies of first-generation EGFR TKIs in untreated patients with advanced EGFR mutation-positive NSCLC

\begin{tabular}{|c|c|c|c|c|c|c|c|c|}
\hline Study & Population & Treatment arms & No. of pts & RR (\%) & \multicolumn{2}{|c|}{ Median PFS } & \multicolumn{2}{|c|}{ Median OS } \\
\hline \multirow[t]{2}{*}{ IPASS } & East Asian & Gefitinib & $609[132]^{*}$ & $43.0(71.2)$ & 9.5 & $0.48 ;<0.001$ & 21.6 & $1.0 ; 0.99$ \\
\hline & Adeno \& nonsmokers & Carbo/pacli & $608[129]^{*}$ & $32.2(47.3)$ & 6.3 & & 21.9 & \\
\hline First- & Korean & Gefitinib & $159[26]^{\star}$ & $55.4(84.6)$ & 8.4 & $0.544 ; 0.086$ & 22.3 & $0.932 ; 0.60$ \\
\hline \multirow[t]{2}{*}{ WJTOG3405 } & Japanese & Gefitinib & 86 & 62.1 & 9.2 & $0.489 ;<0.0001$ & 35.5 & $1.2 ; 0.44$ \\
\hline & EGFR mut & Cis/doce & 86 & 32.2 & 6.3 & & 38.8 & \\
\hline \multirow[t]{2}{*}{ NEJ002 } & Japanese & Gefitinib & 114 & 73.7 & 10.8 & $0.30 ;<0.001$ & 27.7 & $0.88 ; 0.48$ \\
\hline & EGFR mut & Carbo/pacli & 114 & 30.7 & 5.4 & & 26.6 & \\
\hline \multirow[t]{2}{*}{ EURTAC } & European & Erlotinib & 86 & 64 & 9.7 & $0.37 ;<0.0001$ & 19.3 & $1.04 ; 0.87$ \\
\hline & EGFR mut & Platinum CT & 87 & 18 & 5.2 & & 19.5 & \\
\hline \multirow[t]{2}{*}{ ENSURE } & Asian & Erlotinib & 110 & 62.7 & 11 & $0.34 ;<0.0001$ & 26.3 & $0.91 ; 0.61$ \\
\hline & EGFR mut & Cis/gem & 107 & 33.6 & 5.5 & & 25.5 & \\
\hline
\end{tabular}

*, patients with confirmed EGFR mut. EGFR, epidermal growth factor receptor; TKIs, tyrosine-kinase inhibitors; NSCLC, non-small cell lung cancer.

combination of antiangiogenic therapy plus first-generation EGFR TKI.

Several studies conducted in unselected population before the EGFR mutation era highlighted the hypothesis that inhibition of the vascular endothelial growth factor (VEGF) signaling pathway with the monoclonal antibody bevacizumab may have a synergistic effect when added to erlotinib (64). Supported by strong preclinical data that demonstrate increased VEGF levels in EGFR resistant lung cancer xenografts, the interest of the dual anti-EGFR plus anti-VEGF pathway inhibition became of great interest in the front-line setting for EGFR-mutant NSCLC population.

The JO25567 study was a randomized phase II Japanese clinical trial that included 152 patients and evaluated the combination of erlotinib plus bevacizumab versus erlotinib alone (65). A significant benefit in PFS for the combination arm was shown [16.0 versus 9.7 months; HR 0.54; 95\% CI, 0.36-0.79; $\mathrm{P}=0.0015)$. Regarding toxicity profile, a higher incidence of hypertension, proteinuria, and bleeding events was noticed in the combination arm, but overall it was safe and manageable.

The BELIEF study was a phase II single-arm clinical trial that valued the combination of erlotinib plus bevacizumab (66). Pre-treatment T790M was detected in combination to a sensitizing EGFR mutation in 37 out of the 109 patients included in the study. While the median PFS was 13.8 months for the overall population, it was 16.0 months for the T790M-positive subgroup versus 10.5 months for the T790M-negative (unadjusted HR 0.52, 95\% CI, 0.30-0.88; $\mathrm{P}=0.016$ ).

According to the findings of the Japanese and the European trials, bevacizumab plus erlotinib received regulatory approval in Europe, United States, and Asia as a new option of treatment for untreated EGFR-mutant NSCLC patients. The Japanese NEJ026 and the Italian BEVERLY trials are both phase III studies to confirm the benefit of bevacizumab in addition to erlotinib in comparison to erlotinib as single agent. A preplanned interim analysis from the NEJ026 study was submitted at the 2018 ASCO Annual Meeting demonstrating 3.6 months of improvement in PFS for the combination arm, 16.9 versus 13.3 months (HR 0.60; $\mathrm{P}=0.015$ ) (67).

Finally, other antiangiogenic drugs, such as ramucirumab, a monoclonal antibody against VEGF receptor 2, have been evaluated. The RELAY trial is a phase III double-blind 
study that assessed the role of ramucirumab or placebo in addition to erlotinib in the first-line setting of EGFRmutant population. This trial is now closed for recruitment, pending of communication of results (68).

The second strategy to improve survival would be adding chemotherapy to front-line gefitinib. The NEJ009, an open-label, randomized phase III trial (presented at the 2018 ASCO Annual Meeting) was conducted to evaluate the superiority of gefitinib plus carboplatin and pemetrexed $v s$. gefitinib in PFS, PFS2 and OS for untreated Japanese patients with advanced NSCLC with EGFR mutations (69). A sum of 344 patients were included. Although gefitinib plus CT demonstrated significantly better PFS compared to gefitinib (20.9 vs. 11.2 months; HR 0.494, 95\% CI, 0.391 to 0.625; $\mathrm{P}<0.001)$, there was no difference in PFS2 between both arms. Additional OS analysis observed that median OS of gefitinib plus CT was much longer than that of gefitinib (52.2 vs. 38.8 months respectively; HR $0.695,95 \%$ CI, 0.520 to $0.927 ; \mathrm{P}=0.013$ ).

Currently in the field of NSCLC with EGFR mutation have developed second and even third generation TKIs that would be gaining the positioning in the treatment of this subset population of NSCLC Although EGFR first generation TKIs seem to be a second-rate option, without the knowledge that they have provided, we would not have gotten that far. Looking at the past helps us to understand the present and keep working for the future.

\section{Acknowledgments}

None.

\section{Footnote}

Conflicts of Interest: A Martinez-Marti provided consultation, attended advisory boards and/or speaker's bureau for the following organizations: Bristol-Myers Squibb, F. Hoffmann-La Roche, Merck Sharp and Dohme, Pfizer, Boehringer-Ingelheim, AstraZeneca. A Navarro provided consultation, attended advisory boards and/or speaker's bureau for the following organizations: Bristol-Myers Squibb Recipient, F. Hoffman La Roche AG, Pfizer, Boehringer Ingelheim, Oryzon Genomics. E Felip provided consultation, advisory role or speaker's bureau: AbbVie, AstraZeneca, Blueprint medicines, Boehringer Ingelheim, Bristol-Myers Squibb, Celgene, Eli Lilly, Guardant Health, Janssen, Medscape, Merck KGaA, Merck Sharp \& Dohme, Novartis, Pfizer, Roche, Takeda, Touchtime. Research funding: Fundación Merck Salud, Grant for Oncology Innovation EMD Seono.

\section{References}

1. Weinstein IB. Disorders in cell circuitry during multistage carcinogenesis: the role of homeostasis. Carcinogenesis 2000;21:857-64.

2. Weinstein IB. Addiction to oncogenes--the Achilles heal of cancer. Science 2002;297:63-4.

3. Weinstein IB, Joe A. Oncogene Addiction. Cancer Res 2008;68:3077-80.

4. Sharma SV, Gajowniczek P, Way IP, et al. A common signaling cascade may underlie "addiction" to the Src, BCR-ABL, and EGF receptor oncogenes. Cancer Cell 2006;10:425-35.

5. Hynes NE, Lane HA. ERBB receptors and cancer: the complexity of targeted inhibitors. Nat Rev Cancer 2005;5:341-54.

6. Rusch V, Baselga J, Cordon-Cardo C, et al. Differential expression of the epidermal growth factor receptor and its ligands in primary nonsmall cell lung cancers and adjacent benign lung. Cancer Res 1993;53:2379-85.

7. Dutu T, Michiels S, Fouret O, et al. Differential expression of biomarkers in lung adenocarcinoma: a comparative study between smokers and never-smokers. Ann Oncol 2005;16:1906-14.

8. Sequist LV, Lynch TJ. EGFR tyrosine kinase inhibitors in lung cancer: an evolving story. Annu Rev Med 2008;59:429-42.

9. Karp DD, Ferrante KJ, Tensfeldt TG, et al. A phase I dose escalation study of epidermal growth factor receptor (EGFR) tyrosine kinase (TK) inhibitor CP-358,774 in patients (pts) with advanced solid tumors. Lung Cancer 2000;29 Suppl 1:65.

10. Hidalgo M, Siu LL, Nemunaitis J, et al. Phase I and pharmacologic study of OSI-774, an epidermal growth factor receptor tyrosine kinase inhibitor, in patients with advanced solid malignancies. J Clin Oncol 2001;19:3267-79.

11. Baselga J, Rischin D, Ranson M, et al. Phase I safety, pharmacokinetic, and pharmacodynamic trial of ZD1839, a selective oral epidermal growth factor receptor tyrosine kinase inhibitor, in patients with five selected solid tumor types. J Clin Oncol 2002;20:4292-302.

12. Herbst RS, Maddox AM, Rothenberg ML, et al. Selective oral epidermal growth factor receptor tyrosine kinase inhibitor ZD1839 is generally well-tolerated 
and has activity in non-small-cell lung cancer and other solid tumors: results of a phase I trial. J Clin Oncol 2002;20:3815-25.

13. Ranson M, Hammond LA, Ferry D, et al. ZD1839, a selective oral epidermal growth factor receptor-tyrosine kinase inhibitor, is well tolerated and active in patients with solid, malignant tumors: results of a phase I trial. J Clin Oncol 2002;20:2240-50.

14. Goss G, Hirte H, Miller WH Jr, et al. A phase I study of oral ZD 1839 given daily in patients with solid tumors: IND.122, a study of the Investigational New Drug Program of the National Cancer Institute of Canada Clinical Trials Group. Invest New Drugs 2005;23:147-55.

15. Nakagawa K, Tamura T, Negoro S, et al. Phase I pharmacokinetic trial of the selective oral epidermal growth factor receptor tyrosine kinase inhibitor gefitinib ('Iressa', ZD1839) in Japanese patients with solid malignant tumors. Ann Oncol 2003;14:922-30.

16. Grünwald V, Hidalgo M. Development of the epidermal growth factor receptor inhibitor OSI-774. Semin Oncol 2003;30:23-31.

17. Ciardiello F, Caputo R, Bianco R, et al. Antitumor effect and potentiation of cytotoxic drugs activity in human cancer cells by ZD-1839 (Iressa), an epidermal growth factor receptor-selective tyrosine kinase inhibitor. Clin Cancer Res 2000;6:2053-63.

18. Pérez-Soler R, Chachoua A, Hammond LA, et al. Determinants of tumor response and survival with erlotinib in patients with non--small-cell lung cancer. J Clin Oncol 2004;22:3238-47.

19. Fukuoka M, Yano S, Giaccone G, et al. Multiinstitutional randomized phase II trial of gefitinib for previously treated patients with advanced non-smallcell lung cancer (The IDEAL 1 Trial) [corrected]. J Clin Oncol 2003;21:2237-46.

20. Kris MG, Natale RB, Herbst RS, et al. Efficacy of gefitinib, an inhibitor of the epidermal growth factor receptor tyrosine kinase, in symptomatic patients with non-small cell lung cancer: a randomized trial. JAMA 2003;290:2149-58.

21. Jänne PA, Gurubhagavatula S, Yeap BY, et al. Outcomes of patients with advanced non-small cell lung cancer treated with gefitinib (ZD1839, "Iressa") on an expanded access study. Lung Cancer 2004;44:221-30.

22. Veronese ML, Algazy K, Bearn L, et al. Gefitinib in patients with advanced non-small cell lung cancer (NSCLC): the expanded access protocol experience at the University of Pennsylvania. Cancer Invest
2005;23:296-302.

23. Kim KS, Jeong JY, Kim YC, et al. Predictors of the response to gefitinib in refractory non-small cell lung cancer. Clin Cancer Res 2005;11:2244-51.

24. Mohamed MK, Ramalingam S, Lin Y, et al. Skin rash and good performance status predict improved survival with gefitinib in patients with advanced non-small cell lung cancer. Ann Oncol 2005;16:780-5.

25. Giaccone G, Herbst RS, Manegold C, et al. Gefitinib in combination with gemcitabine and cisplatin in advanced non-small-cell lung cancer: a phase III trial--INTACT 1. J Clin Oncol 2004;22:777-84.

26. Herbst RS, Giaccone G, Schiller JH, et al. Gefitinib in combination with paclitaxel and carboplatin in advanced non-small-cell lung cancer: a phase III trial--INTACT 2. J Clin Oncol 2004;22:785-94.

27. Blackhall F, Ranson $M$, Thatcher N. Where next for gefitinib in patients with lung cancer? Lancet Oncol 2006;7:499-507.

28. Herbst RS, Prager D, Hermann R, et al. TRIBUTE: a phase III trial of erlotinib hydrochloride (OSI-774) combined with carboplatin and paclitaxel chemotherapy in advanced non-small-cell lung cancer. J Clin Oncol 2005;23:5892-9.

29. Gatzemeier U, Pluzanska A, Szczesna A, et al. Phase III study of erlotinib in combination with cisplatin and gemcitabine in advanced non-small-cell lung cancer: the Tarceva Lung Cancer Investigation Trial. J Clin Oncol 2007;25:1545-52.

30. Shepherd FA, Rodrigues Pereira J, Ciuleanu T, et al. Erlotinib in previously treated non-small-cell lung cancer. N Engl J Med 2005;353:123-32.

31. Thatcher N, Chang A, Parikh P, et al. Gefitinib plus best supportive care in previously treated patients with refractory advanced non-small-cell lung cancer: results from a randomised, placebo-controlled, multicentre study (Iressa Survival Evaluation in Lung Cancer). Lancet 2005:366:1527-37.

32. Lynch TJ, Bell DW, Sordella R, et al. Activating Mutations in the Epidermal Growth Factor Receptor Underlying Responsiveness of Non-Small-Cell Lung Cancer to Gefitinib. N Engl J Med 2004;350:2129-39.

33. Paez JG, Janne PA, Lee JC, et al. EGFR mutations in lung cancer: correlation with clinical response to gefitinib therapy. Science 2004;304:1497-500.

34. Pao W, Miller V, Zavowski M, et al. EGF receptor gene mutations are common in lung cancers from "never smokers" and are associated with sensitivity of tumors 
to gefitinib and erlotinib. Proc. Natl. Acad. Sci USA 2004;101:13306-11.

35. Mitsudomi T, Kosaka T, Endoh H, et al. Mutations of the epidermal growth factor receptor gene predict prolonged survival after gefitinib treatment in patients with nonsmall-cell lung cancer with postoperative recurrence. J Clin Oncol 2005;23:2513-20.

36. Kosaka T, Yatabe Y, Endoh H, et al. Mutations of the epidermal growth factor receptor gene in lung cancer: biological and clinical implicactions. Cancer Res 2004;64:8919-23.

37. Shigematsu H, Lin L, Takahashi T, et al. Clinical and biological features associated with epidermal growth factor receptor gene mutations in lung cancer. J Natl Cancer Inst 2005;97:339-46.

38. Marchetti A, Martella C, Felicioni L, et al. EGFR mutations in non-small-cell lung cancer: analysis of a large series of cases and development of a rapid and sensitive method for diagnostic screening with potential implicactions on a pharmacologic treatment. J Clin Oncol 2005;23:857-65.

39. Tokumo M, Toyooka S, Kiura K, et al. The relationship between epidermal growth factor receptor mutations and clinicopathologic features in non-small cell lung cancers. Clin Cancer Res 2005;11:1167-73.

40. Han SW, Kim TY, Hwang PG, et al. Predictive and prognostic impact of epidermal growth factor receptor mutation in non-small-cell lung cancer patients treated with gefitinib. J Clin Oncol 2005;23:2493-501.

41. Chou TY, Chiu CH, Li LH, et al. Mutation in the tyrosine kinase domain of epidermal growth factor receptor is a predictive and prognostic factor for gefitinib treatment in patients with non-small cell lung cancer. Clin Cancer Res 2005;11:3750-7.

42. Taron M, Ichinose $Y$, Rosell R, et al. Activating mutations in the tyrosine kinase domain of the epidermal growth factor receptor are associated with improved survival in gefitinib-treated chemo-refractory lung adenocarcinomas. Clin Cancer Res 2005;11:5878-85.

43. Zhang XT, Li LY, Mu XL, et al. The EGFR mutation and its correlation with response of gefitinib in previously treated Chinese patients with advanced non-small-cell lung cancer. Ann Oncol 2005;16:1334-42.

44. Tsao MS, Sakurada A, Cutz JC, et al. Erlotinib in lung cancer- Molecular and clinical predictors of outcome. N Engl J Med 2005;353:133-44.

45. Tomizawa Y, Lijima H, Sunaga N, et al. Clinicopathologic significance of the mutations of the epidermal growth factor receptor gene in patients with non-small cell lung cancer. Clin Cancer Res 2005;11:6816-22.

46. Rosell R, Ichinose Y, Taron M, et al. Mutations in the tyrosine kinase domain of the EGFR gene associated with gefitinib response in non-small-cell lung cancer. Lung Cancer 2005;50:25-33.

47. Riely GJ, Pao W, Pham D, et al. Clinical course of patients with non-small cell lung cancer and epidermal growth factor receptor exon 19 and exon 21 mutations treated with gefitinib or erlotinib. Clin Cancer Res 2006;12:839-44.

48. Jackman DM, Yeap BY, Sequist LV, et al. Exon 19 deletion mutations of epidermal growth factor receptor are associated with prolonged survival in non-small cell lung cancer patients treated with gefitinib or erlotinib. Clin Cancer Res 2006;12:3908-14.

49. Inoue A, Suzuki T, Fukuhara T, et al. Prospective phase II study of gefitinib for chemotherapy-naive patients with advanced non-small-cell lung cancer with epidermal growth factor receptor gene mutations. J Clin Oncol 2006;24:3340-6.

50. Asahina H, Yamazaki K, Kinoshita I, et al. A phase II trial of gefitinib as first-line therapy for advanced non-small cell lung cancer with epidermal growth factor receptor mutations. Br J Cancer 2006;95:998-1004.

51. Tamura K, Okamoto I, Kashii T, et al. Multicentre prospective phase II trial of gefitinib for advanced nonsmall cell lung cancer with epidermal growth factor receptor mutations: results of the West Japan Thoracic Oncology Group trial (WJTOG0403). Br J Cancer 2008;98:907-14.

52. Sequist LV, Martins RG, Spigel D, et al. First-line gefitinib in patients with advanced non-small-cell lung cancer harboring somatic EGFR mutations. J Clin Oncol 2008;26:2442-9.

53. Rosell R, Moran T, Queralt C, et al. Screening for epidermal growth factor receptor mutations in lung cancer. N Engl J Med 2009;361:958-67.

54. Mok TS, Wu YL, Thongprasert S, et al. Gefitinib or carboplatin-paclitaxel in pulmonary adenocarcinoma. N Engl J Med 2009;361:947-57.

55. Han JY, Park K, Kim SW, et al. First-SIGNAL: first-line single-agent iressa versus gemcitabine and cisplatin trial in never-smokers with adenocarcinoma of the lung. J Clin Oncol 2012;30:1122-8.

56. Mitsudomi T, Morita S, Yatabe Y, et al. Gefitinib versus cisplatin plus docetaxel in patients with non-small-cell lung cancer harbouring mutations of the epidermal growth 
factor receptor (WJTOG3405): an open label, randomised phase 3 trial. Lancet Oncol 2010;11:121-8.

57. Yoshioka H, Mitsudomi T, Morita S, et al. Final overall survival results of WJTOG 3405, a randomized phase 3 trial comparing gefitinib $(\mathrm{G})$ with cisplatin plus docetaxel (CD) as the first-line treatment for patients with non-small cell lung cancer (NSCLC) harboring mutations of the epidermal growth factor receptor (EGFR). J Clin Oncol 2014;32:8117.

58. Maemondo M, Inoue A, Kobayashi K, et al. Gefitinib or chemotherapy for non-small-cell lung cancer with mutated EGFR. N Engl J Med 2010;362:2380-8.

59. Inoue A, Kobayashi K, Maemondo M, et al. Updated overall survival results from a randomized phase III trial comparing gefitinib with carboplatin-paclitaxel for chemonaïve non-small cell lung cancer with sensitive EGFR gene mutations (NEJ002). Ann Oncol 2013;24:54-9.

60. Zhou C, Wu YL, Chen G, et al. Erlotinib versus chemotherapy as first-line treatment for patients with advanced EGFR mutation-positive non-small-cell lung cancer (OPTIMAL, CTONG-0802): a multicentre, open-label, randomised, phase 3 study. Lancet Oncol 2011;12:735-42.

61. Zhou C, Wu YL, Chen G, et al. Final overall survival results from a randomised, phase III study of erlotinib versus chemotherapy as first-line treatment of EGFR mutation-positive advanced non-small-cell lung cancer (OPTIMAL, CTONG-0802). Ann Oncol 2015;26:1877-83.

62. Rosell R, Carcereny E, Gervais R, et al. Erlotinib versus standard chemotherapy as first-line treatment for European patients with advanced EGFR mutation-positive non-small-cell lung cancer (EURTAC): a multicentre, open-label, randomised phase 3 trial. Lancet Oncol 2012;13:239-46.

63. Wu YL, Zhou C, Liam CK, et al. First-line erlotinib

Cite this article as: Martinez-Marti A, Navarro A, Felip E. Epidermal growth factor receptor first generation tyrosinekinase inhibitors. Transl Lung Cancer Res 2019;8(Suppl 3):S235S246. doi: 10.21037/tlcr.2019.04.20 versus gemcitabine/cisplatin in patients with advanced EGFR mutation-positive non-small-cell lung cancer: analyses from the phase III, randomized, open-label, ENSURE study. Ann Oncol 2015;26:1883-9.

64. Naumov GN, Nilsson MB, Cascone T, et al. Combined vascular endothelial growth factor receptor and epidermal growth factor receptor (EGFR) blockade inhibits tumor growth in xenograft models of EGFR inhibitor resistance. Clin Cancer Res 2009;15:3484-94.

65. Seto T, Kato T, Nishio M, et al. Erlotinib alone or with bevacizumab as first-line therapy in patients with advanced non-squamous non-small-cell lung cancer harbouring EGFR mutations (JO25567): an open-label, randomised, multicentre, phase 2 study. Lancet Oncol 2014;15:1236-44.

66. Rosell R, Dafni U, Felip E, et al. Erlotinib and bevacizumab in patients with advanced non-small-cell lung cancer and activating EGFR mutations (BELIEF): an international, multicentre, single-arm, phase 2 trial. Lancet Respir Med 2017;5:435-44.

67. Furuya N, Fukuhara T, Saito H, et al. Phase III study comparing bevacizumab plus erlotinib to erlotinib in patients with untreated NSCLC harboring activating EGFR mutations: NEJ026. J Clin Oncol 2018;36:9006.

68. Reck M, Garon EB, Paz-Ares L, et al. Randomized, Double-Blind Phase Ib/III Study of Erlotinib With Ramucirumab or Placebo in Previously Untreated EGFR-Mutant Metastatic Non-Small-Cell Lung Cancer (RELAY): Phase Ib Results. Clin Lung Cancer 2018;19:213-20.e4.

69. Nakamura A, Inoue A, Morita S, et al. Phase III study comparing gefitinib monotherapy $(\mathrm{G})$ to combination therapy with gefitinib, carboplatin, and pemetrexed (GCP) for untreated patients (pts) with advanced non-small cell lung cancer (NSCLC) with EGFR mutations (NEJ009). J Clin Oncol 2018;36:9005. 